\title{
The impact of knowledge management on enterprise innovation capability: the mediation effect of dynamic capability
}

\author{
Qicheng Lu* \\ Business School \\ Yunnan University of Finance and Economics \\ Kunming, China \\ 317404322@qq.com
}

\author{
Linlin Liang \\ International Business School \\ Yunnan University of Finance and Economics \\ Kunming, China \\ 279653205@qq.com
}

\begin{abstract}
Whether knowledge management has a positive impact on enterprise's innovation capability is still a controversial topic, and the mechanism of its influences is still very vague. This paper explores the influence of knowledge management on enterprise innovation capability under the unified framework of dynamic capability. With empirical study in 248 companies we found that knowledge management had significantly positive influence on enterprise innovation capability, and dynamic capabilities have full mediating effect in knowledge management on enterprise innovation relations. Under the dynamic capability framework, the influences of knowledge management on innovation capability need to be realized through the mediation role of dynamic capability. This paper reveals that knowledge management could reconstruct and promote innovation capabilities through dynamic capability sensing and seizing environmental changes.
\end{abstract}

Keywords-innovation capability; knowledge management; dynamic capability; mediation effect

\section{INTRODUCTION}

Organizational innovation is considered to be an important source of sustainable competitive advantage enterprises for it can bring about new products, new services and the development of new management system[1-2]. The innovation process involves the acquisition, dissemination and use of existing knowledge and existing knowledge. Organizational innovation is closely related to the capability to use knowledge resources[3].

However, research on how companies' existing knowledge affects innovation remains controversial[4]. Reference [5] believes that the accumulation of knowledge is not always beneficial, and that the accumulation of knowledge may lead to a core rigidity which can generate path dependencies that is not conducive to innovation. It is believed that deep knowledge in specific areas can lead to breakthroughs in the implementation of major ideas. Many companies can put forward a lot of attractive ideas, but it failed to meet due to the difficulties in the execution of innovation for the reason of lack of adequate professional knowledge to solve the problem of many complicated unconventional. Reference [6] points out that although the diversified knowledge can inspire more

\footnotetext{
* Corresponding author
}

creative, diverse knowledge will distract the enterprise investment and lead to the lack of enough comprehensive integration and utilization which will make these ideas just hit a shallow surface and hardly penetrate the root cause to achieve breakthrough innovation. The existing knowledge management research has difficulty in explaining why there is a huge differences with the same knowledge management platform and the result of the strategy of enterprise based on knowledge [7].

The success of innovation depends not only on the ability of the enterprise to acquire and apply new knowledge, but also on the perception and rapid response of the enterprise to the external environment, especially the market. This requires companies to perceive to environmental changes and respond quickly, then the companies should integrate internal and external knowledge and other resources with changing the organizational structure, resource configuration mode, operation processes and practices, and finally the companies will realize the innovation in product and process change. Existing research has also found significant positive impact on management innovation[8], technical innovation capacity[9]. Therefore, in view of the above dispute this paper research addresses this gap, this paper exploratory puts forward to analyze the relations between knowledge management (KM) and the enterprise innovation capability under the framework of dynamic capability (DC). This paper try to answer the following questions: Does knowledge management have a positive effect on enterprise innovation ability? What is the role of dynamic capacity knowledge management in influencing innovation?

\section{THEORETICAL BASIS AND RESEARCH HYPOTHESIS}

Innovation depends on creation and composition of knowledge[10]. Successful knowledge management and organizational learning lead to more effective enterprise innovation performance, and ultimately affect success rate of new products and services in the marketplace[7]. Gaining knowledge from external markets and internal employees creates opportunities for companies to integrate existing knowledge and create new knowledge. The interaction between new knowledge and enterprise existing knowledge 
could correct, improve knowledge base and improve the width and depth of enterprise reserve knowledge, and further enhance the potential to produce new innovation. Knowledgebased View believes that knowledge acquisition can effectively improve enterprise capacity. With strong internal and external knowledge acquisition ability, the enterprises could achieve differentiated success in management and technology. Therefore, this paper thinks that knowledge acquisition has positive effect on enterprise innovation capability. Because knowledge is distributed across different individuals and levels within the organization, organizational members need to share knowledge to establish new conventions and new mental models. Because knowledge is distributed across different individuals and levels within the organization, organizational members need to share knowledge to establish new conventions and new mental models. Meanwhile, only individuals have the willingness to share knowledge and communicate, they can produce collective learning and synergies from the communication process of knowledge and resources. When organization shares its expertise and makes it explicit in the form of a product or service, the enterprise achieves innovation. As a result, companies that are able to implement knowledge effectively in the organization are more innovative. Knowledge-based Views thought that since knowledge is characterized by stickiness and tacitness, the value of individual and organizational knowledge lies largely in the application process. New products development and innovation requires an application and combination of expertise from all fields. The depth of knowledge enables companies to continuously organize their expertise in physical products. Through effective knowledge application, individuals can make fewer mistakes and eventually be able to accelerate new product development with more innovative products processing technology and management system. Therefore, this paper assumes:

H1: Knowledge management (KM) has a significant positi ve impact on innovation capacity (IC)

Dynamic capabilities framework attempts to explain how enterprise can make its flexibility to cope with the industry changes without losing competitive advantage by developing strategic practice and ability to. Organizational learning is a major way for the enterprise to improve and update the dynamic capability. Recent studies have also found that knowledge management is another important path to develop and maintain the dynamic capability. It is found that the efficient use of knowledge management systems helps executives identify new market opportunities. Reference [11] found in mature industries that dynamic and knowledge management interactions can improve enterprise's exports performance. Based on the perspective, knowledge acquisition and transfer, as well as benefit from external knowledge and innovation can be considered in the rapidly changing external market the series of activities to obtain sustainable competitive advantage of making decision support enterprises. Reference [12] points out that open innovation is not only a process of embracing external knowledge and innovation, but also a driving force for change. Therefore, the dynamic capability View integrates the content view and process of knowledge management as the key resource of competitive advantage to realize enterprise innovation. The essence of innovation is the usefulness and commercialization of knowledge. And the success of the process depends not only on the ability to acquire and apply new knowledge but more on enterprise external environment, especially the market awareness and quick response. This requires companies to perceive environmental changes and respond quickly, integrate internal and external knowledge and other resources, change the existing organizational structure, resource configuration mode, operation processes and practices, refactoring operation ability, realize the innovation in product and process change. Namely, the enterprise successful innovation depends on the operation of dynamic capabilities, only knowledge activity management ability is difficult to guarantee the high performance of innovation, promote the innovation ability of ascension. Therefore, this paper assumes:

H2: Dynamic capability (DC) has a significant positive i mpact on innovation capability

Existing studies have identified the factors that limit and threaten companies to gain competitive advantage from knowledge, such as knowledge transfer difficulties and high costs resulting from stickiness knowledge stickiness. Knowledge embeddedness impedes the effective transfer of knowledge and limits the replication of the same knowledge in different contexts. Complex tacit knowledge creates the vagueness of strategic assets that limits the intent of the enterprise to learn and copy successful strategies. Innovation is the new integration of new and old knowledge-oriented enterprises. According to Knowledge-based views, integrated knowledge ability depends on two factors. First is the level of knowledge resources, namely the knowledge base of the enterprise, second is the enterprise integration mechanism of knowledge. The enterprise's knowledge base (knowledge reserve) determines the scope and capacity of the enterprise to comprehend and apply new knowledge to the radical innovation. Successful product development requires not only the knowledge base, but also the knowledge integration mechanism to acquire, interpret and configure its knowledge resources. Enterprise quickly awareness and ability of rapid transformation enable enterprises to cope with environmental changes, change practice, update and application of knowledge and information, help enterprises in many competitors to take the lead in exploring new markets or developing new products and services to meet the new requirements, maintain and continuously improve the innovation performance of enterprise. Based on the results of a sample of 120 Internet companies, it is shown that the ability of companies to be innovative in their resources and their ability to integrate. In addition, we also find that the relevant relationship between resource stock and innovation is mediated by integration capabilities. That is, just having a good resource endowment is essentially not enough to affect innovation. Therefore, the enterprise in mobilizing resources and capabilities and dynamically with the changes in the environment of the opportunity to match the ability of innovation for survival of the enterprise or create its competitive advantage is very important. This dynamic capabilities demand is even more important in hyper- 
competitive and rapidly changing internet-based environments Therefore, this paper assumes:

H3 : Dynamic capability has a mediating effect on the relationship between knowledge management (KM) and innovation capability (IC)

$\mathrm{H} 3 \mathrm{a}$ : Sensing response (DC1) is mediated by the relationship between knowledge management and the ability to innovate

$\mathrm{H} 3 \mathrm{~b}$ : Seizing integrated (DC2) is mediated by the relationship between knowledge management and innovation ability

$\mathrm{H} 3 \mathrm{c}$ : Reconfiguring transformations (DC3) are mediated by the relationship between knowledge management and innovation capability

\section{RESEARCH DESIGN}

\section{A. Data collection and sample characteristics}

Because data of organizational learning, knowledge management and dynamic capabilities cannot be obtained from public data, this paper adopt the way of large-scale enterprise questionnaire for data collection and the empirical analysis. The investigation eventually recovers 323 questionnaires, the recovery rate of $80.75 \%$, effective questionnaire 248 , effectiveness $76.78 \%$. Invalid questionnaire mainly subjects in the enterprise set up less than three years and questionnaire fill-rate lower than $95 \%$. Based on the basic characteristics of the survey sample, the survey respondents were found to have formed 80 percent of the time in five years.

\section{B. Variable measurement}

\section{1) Dynamic capability}

Dynamic capability is a meta-practice that systematically creates, extends, and adjusts the set of business practices in order to adapt to the dynamic changes of the environment. It involves the integration and utilization of internal and external resources, the modification, promotion and reconstruction of the business practices. This paper divides dynamic capabilities into three dimensions: sensory response, integration and reconstruction. Questionnaire design main reference research, respectively design, 4 of the cognitive response to four item, 5 of integrated use, 3 of transformation of refactoring to measure dynamic capabilities.

\section{2) Knowledge management}

Knowledge management is the process that enterprise continuously search and create knowledge to achieve longterm interests, manage knowledge flow to promote knowledge sharing and efficient application. Based on the process perspective, this paper measures the ability and level of enterprise knowledge management ability and level from knowledge acquisition, knowledge sharing and knowledge application. Respectively literature research, this paper design 4 of knowledge acquisition, knowledge sharing, 5 of knowledge application, 5 of knowledge application, a total of 14 item to measure knowledge management.

\section{3) Innovation capability}

Innovation capability is the capability of enterprise to introduce new processes, new products or new ideas, and generate revenue for the company and its shareholders.

Questionnaire uses Grade five Likert scale method to fill in personnel from "1- strongly disgree, 2 - doesn't conform to, 3 not sure, 4 - compared with 5 - very accord with" grade evaluation. In order to obtain 248 valid samples, the mean, standard deviation and correlation coefficient of the valid sample variables were obtained.

\section{Reliability and validity test}

Analysis found that the measurement of Cronbach's alpha coefficients were greater than 0.7 , the reliability of inspection item - the overall correlation coefficient (CITC) is greater than 0.50 which indicates that variable measure has high internal consistency. In the scale of the second-order CFA model, 7 measurement dimensions are significant factors of load path coefficient, load factor values were higher than 0.71 , it is said the individual potential construct can explain the variance of measured variables were greater than $50.0 \%$. it show that each potential construct measure variables can effectively reflect its corresponding latent trait. By means of "Average deviation extraction, AVE", this paper analyzes the convergent validity of measurement scale. AVE is a potential variable which can explain the index variance ratio. The greater the numerical means the more measure can effectively reflect the common factor construct of the latent trait. AVE of knowledge management, the dynamic capability were $0.603,0.727,0.707$, innovation capability of AVE is 0.700 , which were higher than the critical value of 0.50 , which represents measurement model has good convergent validity.

\section{RESULTS AND DISCUSSIONS}

\section{A. Direct effect test}

This paper build structural equation model with AMOS17.0. Firstly, this paper tests the direct path coefficient organizational learning, knowledge management and dynamic capabilities and innovation capability. The result shows that knowledge management and dynamic capability to innovation capability of the path coefficient was $0.804(\mathrm{t}=16.662)$ and $0.881(\mathrm{t}=16.336)$. It shows that knowledge management and dynamic capabilities have positive impact on innovation ability, which confirms $\mathrm{H} 1$ and $\mathrm{H} 2$.

\section{B. Mediation test}

This paper further proves the dynamic capability is in the mediation role of relationship between knowledge management and innovation ability. Model results show that the dynamic capability of three dimensions is in the partial intermediary role between knowledge management and dynamic capabilities. Proportion of cognitive response, integrated utilization and reconstruction the mediation effect is respectively $0.242,0.321$ and 0.306 in the total effect, which confirmed $\mathrm{H} 3 \mathrm{a}, \mathrm{H} 3 \mathrm{~b}$ and $\mathrm{H} 3 \mathrm{c}$. 


\section{CONCLUSION}

This paper examined the influence of knowledge management and dynamic capability on enterprise innovation capability with 248 enterprises' survey data under the unified framework of dynamic capability. It found that: (1) knowledge management and dynamic capability were significantly positive influence on the enterprise innovation capability, and dynamic capabilities have full mediating effect in the relations between knowledge management and enterprise innovation. (2) under dynamic capability framework, the impact of knowledge management on innovation ability needs to be achieved through the mediation role of dynamic capability, (3) three dimensions of dynamic capability, sensing response, seizing integrated and reconfiguring transformation plays a partial mediation effect of different level in the relationship between knowledge management and innovation capability, of which the seizing integrated of mediation effect more significance.

\section{ACKNOWLEDGMENT}

The paper is supported by the National Natural Science Foundation of China (No.71362014), China postdoctoral science foundation project (No. 2015M570494).

\section{REFERENCES}

[1] F. Damanpour, "Organizational innovation: a meta-analysis of effects of determinants and moderators," Academy of Management Journal, vol. 34, pp. 555-590, March 1991.

[2] R.F. Hurley, G.T. Hult, R.M. Hurley and T. Hult, "Innovation, Marketing Orientation, and Organizational Learning: An Integration and Empirical Examination," Journal of Marketing, vol. 62, pp. 42-54, July 1998.
[3] M. Subramaniam, and M.A. Youndt, "The influence of intellectual capital on the types of innovative capabilities," Academic Management Journal, March 2005, vol. 48, pp. 450-63.

[4] K.Z. Zhou, and C.B. Li, "How knowledge affects radical innovation: Knowledge base, market knowledge acquisition, and internal knowledge sharing," Strategic Management Journal, vol. 33. pp. 1090 1102, September 2012.

[5] D. Leonard-Barton, "Core competence and core hardness: management of contradictions in the development of new products," Strategic Management Journal, vol. 13 pp. 111-125, 1992.

[6] K. Laursen, and A. Salter, "Open for innovation: the role of openness in explaining innovation performance among U.K. manufacturing firms," Strategic Management Journal, vol.27, pp. 131-150, February 2006.

[7] D. Schneckenberg, Y. Truong, and H. Mazloomi, "Microfoundations of innovative capabilities: The leverage of collaborative technologies on organizational learning and knowledge management in a multinational corporation," Technological Forecasting \& Social Change, vol. 100, pp. 356-368, August 2015.

[8] H.F. Lin, J.Q. Su and A. Higgins, "How dynamic capabilities affect adoption of management innovations," Journal of Business Research, vol. 69, pp. 862-876, February 2016.

[9] D.J. Teece, "Strategies for managing knowledge assets: the role of firm structure and industrial context," Long Range Plan, vol. 33, pp. 35-54, January 2000.

[10] I. Nonaka, and H. Takeuchi, "The Knowledge-creating Company: How Japanese Companies Create the Dynamics of Innovation," Oxford University Press, 1995, New York.

[11] C. Villar, J. Alegre, and J. Pla-Barber, "Exploring the role of knowledge management practices on exports: A dynamic capabilities view," International Business Review, vol. 23, pp. 38-44, January 2013.

[12] D.J. Teece, G. Pisano, and A. Shuen, "Dynamic Capabilities and Strategic Management," Strategic Management Journal, vol. 18, pp. 509-533, July 1997. 